\title{
Medial temporal lobe epilepsy: gender differences
}

\author{
J Janszky, R Schulz, I Janszky, A Ebner
}

J Neurol Neurosurg Psychiatry 2004;75:773-775. doi: 10.1136/jnnp.2003.020941

The present study investigated the gender differences in medial temporal lobe epilepsy (MTLE) with regard to clinical history, seizure semiology, and EEG data. To avoid the influence of pathological and localisation differences, we included only MTLE patients with hippocampal sclerosis. Patients who had long term video EEG recordings with registered seizures and unilateral hippocampal sclerosis proved by high resolution MRI were included. There were 153 patients ( 86 women and 67 men) who met our inclusion criteria. The mean age of the patients was 33.5 years (range 16-59). The mean age at epilepsy onset was 10.8 years. Although there were more women than men, this difference was not significant $(p=0.15)$. We found that male patients experienced generalised seizures significantly more often, and isolated auras significantly less often than female patients. Analysing EEG data, we found that a seizure pattern lateralised to the side of the hippocampal sclerosis occurred more often in female patients. In the logistic regression analysis, we found that all three factors were associated independently with gender. Odds ratio (OR) for female gender in patients with generalised seizures was 0.44 (95\% confidence interval $(95 \% \mathrm{Cl}) 0.21$ to 0.92 ; $\mathrm{p}<0.05)$. In patients with isolated auras $O R$ for female gender was 2.1 (95\% Cl 1.1 to $4.2 ; \mathrm{p}<0.05)$. OR for female gender in patients with lateralised seizure pattern was 8.8 (95\% Cl 1.8 to $42.7 ; \mathrm{p}<0.01)$. Men more often had secondarily generalised tonic-clonic seizures, while women had isolated auras and lateralised EEG seizure pattern more often. Our data suggest that the seizure spread is more extended or occurs more frequently in men than in women.

$\mathrm{T}$ he incidence and prevalence of epilepsy and the risk for the first unprovoked seizure is higher in men than in women, which seems true even after the higher incidence of epilepsy risk factors in males is taken into account. ${ }^{1}$ Although there are some data to indicate that the epilepsies of men and of women are different in some aspects, little is known about gender differences in the whole clinical picture. Sexual auras are more frequent in women than in men, ${ }^{23}$ while men may be more vulnerable to seizure associated brain damage. ${ }^{4}$

The present study investigated the gender differences in temporal lobe epilepsy (TLE) with regard to clinical history, seizure semiology, and EEG data. To avoid the influence of pathological and localisation differences, we included only patients suffering from medial TLE (MTLE). MTLE accompanied by hippocampal sclerosis (HS) is a unique, homogenous epilepsy syndrome; moreover, it is the most frequent chronic focal epilepsy. ${ }^{5}$ Gender differences can be clearly investigated in MTLE, a homogenous focal epilepsy syndrome, as these patients have the same pathology in the same location.

\section{METHODS \\ Patients}

In this retrospective study, we included all patients who consecutively underwent presurgical evaluation at our centre from 1994 to 2002 and had intractable MTLE associated with HS. Only patients who had long term video EEG and registered seizures were included. Our further inclusion criteria were: (a) complex partial seizures (CPS) proved by ictal video EEG; (b) definitive inter-ictal epileptiform discharges (spikes or sharp waves) over one or both temporal regions; or (c) unilateral hippocampal sclerosis detected by high resolution MRI. We defined HS if both hippocampal atrophy and increased T2 signal intensity in the hippocampus were present on MRI by visual inspection. Patients with bilateral HS or dual pathology (HS accompanied by other epileptogenic lesion) were excluded. To make our study population as homogenous as possible, we did not include patients who had epilepsy risk factors other than febrile seizures, or a family history of epilepsy that may have indicated an extended epileptic region other than the mesiotemporal area.

\section{METHODS}

The data regarding the age at the first unprovoked seizure, usual seizure frequency, presence of generalised tonic-clonic seizures, and presence and type of aura were derived from medical records registered at admission to the presurgical unit.

\section{Video EEG monitoring}

Patients underwent continuous video scalp EEG monitoring lasting $>2$ days. A 64 channel computerised EEG was used, with the electrodes placed according to the 10-10 system. The inter-ictal EEG samples were automatically recorded and stored on computer. In this study, the first 2 minutes of each computer recorded hour were reviewed and evaluated manually by visual inspections. Ictal EEG data were recorded in files separate from the inter-ictal files. The analysis of seizure semiology and EEG data was based on the long term video EEG recordings. Inter-ictal epileptiform discharges were defined as unilateral if $>95 \%$ of inter-ictal discharges appeared over one temporal lobe. Ictal EEG recordings were categorised as lateralised to the side of the HS, lateralised to the contralateral temporal lobe, or not lateralised. Delayed lateralisation was categorised as equivalent to initial lateralisation.

\section{MRI investigations}

The examinations were made on 1.5 or 1.0 Tesla Siemens Magnetom MR scanners (Siemens, Erlangen, Germany). Scout views with careful slides were used to avoid asymmetry, and then sagittal T1, axial T2, coronal T1 and T2, and proton density or FLAIR sequences perpendicular to the long

Abbreviations: HS, hippocampal seizures; MTLE, medial temporal lobe epilepsy; TLE, temporal lobe epilepsy 
axis of the hippocampus were made, giving adequate delineation of the temporal lobes.

\section{Statistical methods}

For statistical analysis of categorical data, $\chi^{2}$ and Fisher's exact tests were carried out. For continuous variables, MannWhitney $U$ test was performed. In order to establish the variables that are associated independently with gender, a stepwise forward logistic regression analysis was designed for all variables.

\section{RESULTS}

There were 153 patients (86 women and 67 men) who met our inclusion criteria. The mean age of the patients was 33.5 years (range 16-59). In 69 patients, the HS was on the right side, and in 84 patients on the left. Although there were more women than men, this difference was not significant $(\mathrm{p}=0.15$, binomial test $)$.

The mean age at epilepsy onset was 10.8 years. In the 84 patients with left sided HS, epilepsy began at a mean (SD) age of 10.7 (8) in women and 9.8 (8) in men. In the 69 patients with right sided HS, epilepsy started at 11.1 (9) years of age in women and 12.0 (8) years in men. These differences were not significant.

We found no difference in the two sexes for general epileptological data and clinical history (see table 1). Concerning seizure semiology and characteristics, we found that male patients experienced generalised seizures significantly more often, and isolated auras significantly less often than female patients. Analysing EEG data, we found that a seizure pattern lateralised to the side of the hippocampal sclerosis occurred more often in female patients (see table 1).

In the logistic regression analysis, we found that all three factors were associated independently with gender. Odds ratio (OR) for female gender in patients with generalised seizures was 0.44 (95\% confidence interval (CI) 0.21 to 0.92 ; $\mathrm{p}<0.05)$, for isolated auras 2.1 (95\% CI 1.1 to $4.2 ; \mathrm{p}<0.05)$, and for lateralised seizure pattern 8.8 (95\% CI 1.8 to 42.7 ). The latter CI was relatively wide owing to the small number of patients with non-lateralised seizure pattern; however, this difference was also significant $(\mathrm{p}<0.01)$.

\section{DISCUSSION}

The main result of our study investigating gender differences in patients with MTLE was that men more frequently experienced secondarily generalised tonic-clonic seizures, while women had isolated auras and lateralised EEG seizure pattern more often.

Recently, Doherty et al found that in men with right sided epilepsy, seizures began earlier than in those with left sided discharges, whereas women showed the opposite trend. ${ }^{6}$ We did not find such a difference, but our population was smaller. Conversely, we studied a homogenous epilepsy syndrome, while Doherty et al included mixed epilepsy syndromes with various aetiology.

A PET study found that men with MTLE had ipsilateral frontal hypometabolism more frequently and contralateral hypometabolism less frequently compared with women. ${ }^{7}$ Because PET hypometabolism may be related to seizure spread, ${ }^{89}$ these data may also suggest that seizures may spread in different patterns in men than in women. Consequently, our findings showing that secondarily generalised seizures occurred more frequently, while isolated auras appeared less frequently in men suggest that seizure propagation in men is different or more widespread than in women. Our observation of a lateralised EEG seizure pattern seen more often in women than in men also supports this interpretation.
Table 1 General data, clinical history, seizure semiology, and EEG data of patients

\begin{tabular}{|c|c|c|c|c|}
\hline & $\begin{array}{l}\text { All patients } \\
(n=153)\end{array}$ & $\begin{array}{l}\text { Men } \\
(n=67)\end{array}$ & $\begin{array}{l}\text { Women } \\
(n=86)\end{array}$ & $\begin{array}{l}p \\
\text { value }\end{array}$ \\
\hline Age at onset (years) ${ }^{*}$ & $10.8(8)$ & 10.8180 & $10.8(8)$ & NS \\
\hline $\mathrm{Age}^{*}$ & $33.5(10)$ & $33(10)$ & $33.9(11)$ & NS \\
\hline $\begin{array}{l}\text { Duration of epilepsy } \\
\text { (years)* }\end{array}$ & $22.6(11)$ & $22.1(11)$ & $23(110)$ & NS \\
\hline $\begin{array}{l}\text { History of febrile } \\
\text { seizures }\end{array}$ & 91 (59\%) & $39(58 \%)$ & $52(60 \%)$ & NS \\
\hline $\begin{array}{l}\text { Family history of } \\
\text { epilepsy }\end{array}$ & $11(7 \%)$ & $6(9 \%)$ & $5(6 \%)$ & NS \\
\hline $\begin{array}{l}\text { Left hippocampal } \\
\text { sclerosis }\end{array}$ & $84(55 \%)$ & $36(54 \%)$ & $48(56 \%)$ & NS \\
\hline $\begin{array}{l}\text { Monthly number of } \\
\text { seizures, mean (SD) } \\
\text { (median) }\end{array}$ & $\begin{array}{l}8.9(15) \\
(5)\end{array}$ & $\begin{array}{l}9.4(18) \\
(4)\end{array}$ & $\begin{array}{l}8.5(13) \\
(5)\end{array}$ & NS \\
\hline \multicolumn{5}{|l|}{ Aura } \\
\hline None & $14(9 \%)$ & $9(13 \%)$ & $5(6 \%)$ & NS \\
\hline Isolated & $83(54 \%)$ & $30(45 \%)$ & $53(62 \%)$ & 0.03 \\
\hline Abdominal & $98(64 \%)$ & $39(58 \%)$ & $59(69 \%)$ & NS \\
\hline Psychic & $43(28 \%)$ & $16(24 \%)$ & $27(31 \%)$ & NS \\
\hline Olfactory & $5(3 \%)$ & $2(3 \%)$ & $3(3 \%)$ & NS \\
\hline Auditory & $4(3 \%)$ & $2(3 \%)$ & $2(2 \%)$ & NS \\
\hline $\begin{array}{l}\text { Complex partial } \\
\text { seizures }\end{array}$ & $153(100 \%)$ & 67 (100\%) & $86(100 \%)$ & NS \\
\hline $\begin{array}{l}\text { Secondarily } \\
\text { generalised seizures }\end{array}$ & 97 (63\%) & $49(73 \%)$ & $48(56 \%)$ & 0.03 \\
\hline Oral automatisms & $115(75 \%)$ & 48 (71\%) & 67 (78\%) & NS \\
\hline Dystonic posturing & $66(43 \%)$ & $29(43 \%)$ & $37(43 \%)$ & NS \\
\hline Ictal speech & $24(16 \%)$ & $8(12 \%)$ & $16(19 \%)$ & NS \\
\hline Postictal aphasia & $43(28 \%)$ & $17(25 \%)$ & $26(30 \%)$ & NS \\
\hline $\begin{array}{l}\text { Seizure pattern } \\
\text { lateralised to the side } \\
\text { of hippocampal sclerosis }\end{array}$ & $140(92 \%)$ & $56(84 \%)$ & 84 (98\%) & $<0.01$ \\
\hline $\begin{array}{l}\text { Presence of } \\
\text { contralateral seizure } \\
\text { pattern }\end{array}$ & $11(7 \%)$ & $6(9 \%)$ & $5(6 \%)$ & NS \\
\hline $\begin{array}{l}\text { Bitemporal independent } \\
\text { interictal epileptiform } \\
\text { discharges }\end{array}$ & $43(28 \%)$ & $20(30 \%)$ & $23(27 \%)$ & NS \\
\hline
\end{tabular}

The assumption that seizures in men show more or different propagation than in women is in agreement with other human and experimental studies. Although the hippocampus ipsilateral to the seizure focus in MTLE is smaller in both genders equally, the hippocampus contralateral to the seizure onset is more affected in men than in women. ${ }^{4}$ The atrophy of the contralateral hippocampus is thought to be associated with seizure associated brain damage. ${ }^{4}$ This may suggest that in men the seizure spread is more extended. Animal models of MTLE using pilocarpin and kainic acid indicate that males are more susceptible to TLE than females. ${ }^{10}$ Moreover, temporal lobe seizures in male animals are more severe than in female animals. These gender differences may be related to the testosterone level. ${ }^{10}$

The main limitation of this study is its retrospective nature, especially regarding the anamnestic data. However, our study may facilitate future prospective studies investigating clinical gender differences in epilepsy.

\section{ACKNOWLEDGEMENTS}

This work was supported by a grant from the Deutsche Forschungsgemeinschaft (DFG-Eb 111/2-2) and from the Humboldt Stiftung (Dr J Janszky). We gratefully acknowledge T Shore Ebner for help with the English language.

\section{Authors' affiliations J Janszky, R Schulz, A Ebner, Epilepsy Center Bethel, Bielefeld, Germany}


J Janszky, National Institute of Psychiatry and Neurology, Budapest, Hungary

I Janszky, Department of Public Health Sciences, Karolinska Institute, Stockholm, Sweden

Competing interests: none declared

Correspondence to: Dr J Janszky, Epilepsie-Zentrum Bethel, Mara Krankenhaus, Maraweg 21, Bielefeld 33617, Germany; e-mail: janszky@index.hu

Received 17 June 2003

In revised form 16 September 2003

Accepted 4 October 2003

\section{REFERENCES}

1 Hauser WA. Incidence and prevalence. In: Engel J, Pedley TA, eds. Epilepsy: A comprehensive textbook. Philadelphia: Lippincot-Raven Publishers, 1997:47-58.
2 Remillard GM, Andremann F, Testa GF, et al. Sexual ictal manifestations predominate in women with temporal lobe epilepsy: a finding suggesting sexual dimorphism in the human brain. Neurology 1983;33:323-30.

3 Janszky J, Szücs A, Halász $P$, et al. Orgasmic aura originates from the right hemisphere. Neurology 2002;58:302-4.

4 Briellmann RS, Berkovic SF, Jackson GD. Men may be more vulnerable to seizure-associated brain damage. Neurology 2000;55:1479-85.

5 French JA, Williamson PD, Thadani VM, et al. Characteristic of medial temporal lobe epilepsy: I. Results of history and physical examination. Ann Neurol 1993:34:774-80

6 Doherty MJ, Jayadev S, Miller JW, et al. Age at focal epilepsy onset varies by sex and hemispheric lateralization. Neurology 2003;60:1473-7.

7 Savic I, Engel J. Sex differences in patients with mesial temporal lobe epilepsy. J Neurol Neurosurg Psychiatry 1998;65:910-12.

8 Savic I, Altshuler L, Baxter L, et al. Pattern of interictal hypometabolism in PET scans with fludeoxyglucose $F 18$ reflects prior seizure types in patients with mesial temporal lobe seizures. Arch Neurol 1997;54:129-36.

9 Arnold S, Schlaug G, Niemann H, et al. Topography of interictal glucose hypometabolism in unilateral mesiotemporal epilepsy. Neurology 1996;46:1422-30.

10 Mejias-Aponte CA, Jimenez-Rivera CA, Segarra AC. Sex differences in models of temporal lobe epilepsy: role of testosterone. Brain Res 2002;944:210-18.

\section{NEUROLOGICAL PICTURE}

\section{An unusual case of thigh adductor weakness: obturator nerve ganglion}

A 34 year old sportsman suffered from thigh adduction weakness and moderate adductor muscle atrophy with unspecific pain at the pelvic region. After deterioration of the symptoms and exclusion of muscle lesion by ultrasound, neurological examination and EMG diagnosed an isolated obturator motor neuropathy. A tumour measuring $3 \times 2 \times 1.5 \mathrm{~cm}$ was detected by MRI and sonographically guided biopsy confirmed mucous content of the cyst. Upon surgical exploration the tumour was visualised in the obturator foramen, compressing the obturator nerve between the pubic bone ramus and the external obturator muscle (fig 1). Decompression of the obturator nerve was successfully done by

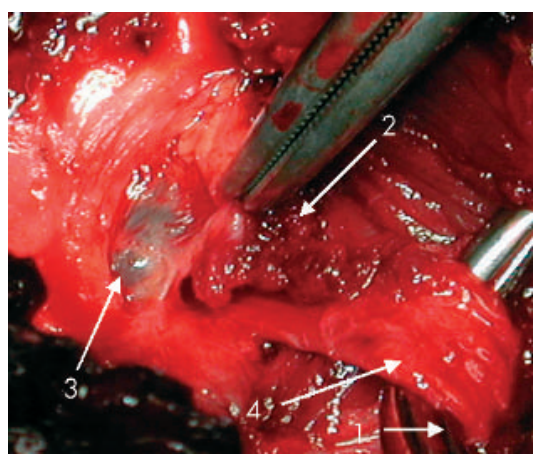

Figure 1 Intraoperative picture showing the obturator ganglion in situ just before its removal. Arrow 1, long adductor muscle; arrow 2 , pectineus muscle; arrow 3, ganglion; arrow 4, obturator nerve.

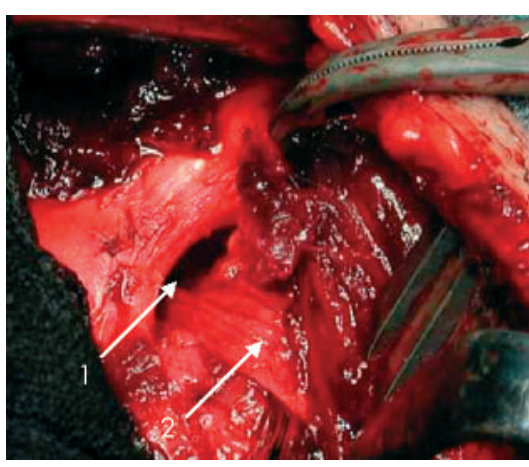

Figure 2 Decompression of the obturator nerve after the ganglion was extirpated. Arrow 1 , note the potential space developed above the nerve after removal of the ganglion; arrow 2, obturator nerve.

extirpation of the ganglion (fig 2). Nerve stimulation at the level of tumour resection revealed contractibility of all the adductor muscles. Immobilisation of the thigh (preventing abduction and external rotation) was advised for three weeks and forced muscle training started not earlier than six weeks after the surgery to allow sufficient pectineus muscle reattachment. After intensive rehabilitation the adductor muscles regained normal clinical function verified by EMG at four month follow up.

Obturator neuropathy due to a ganglion is a rare entity that requires a continuing investigation to verify the exact diagnosis. In addition to a complete neurological examination, colour
Doppler ultrasound, MRI, EMG, and eventually fine needle aspiration biopsy are usually required to confirm the diagnosis. Surgical treatment is usually successful when performed early, but, when diagnosis is delayed, tumour growth may cause irreversible axonal injury and muscle palsy. This report illustrates the importance of timely diagnosis and treatment of a seldom case of obturator neuropathy. ${ }^{1-5}$

A H Schwabegger, M Shafighi, R Gurunluoglu Department of Plastic and Reconstructive Surgery, Ludwig Boltzmann Institute for Quality Control in Plastic Surgery, Leopold-Franzens University Clinic Innsbruck, Austria

Correspondence to: $\operatorname{Dr}$ A H Schwabegger, Department of Plastic and Reconstructive Surgery, Leopold-Franzens University Innsbruck, Anichstrasse 35, A-6020 Innsbruck, Austria; anton.schwabegger@uibk.ac.at

\section{References}

1 Aubert J, Debiais F, Levillain P. Schwannoma of the obturator nerve with urologic manifestations: report of a case. Ann Urol (Paris) 2000;34:58-65.

2 Bradshaw C, McCrory P, Bell S, et al. Obturator nerve entrapment. A cause of groin pain in athletes. Am J Sports Med 1997;25:402-8

3 Crews DA, Dohlman LE. Obturator neuropathy after multiple genitourinary procedures. Urology 1987;29:504-505.

4 Warfield CA. Obturator neuropathy after forceps delivery. Obstet Gynecol 1984;64:4-48.

5 Yang KH, Han DY, Park HW, et al. Intraarticular entrapment of the obturator nerve in acetabular fracture. J Orthop Trauma 2001;15:361-3. 